Check for updates

Cite this: RSC Adv., 2017, 7, 38160

Received 21st June 2017

Accepted 9th July 2017

DOI: $10.1039 / \mathrm{c} 7 \mathrm{ra06915d}$

rsc.li/rsc-advances

\section{A supramolecular self-assembly host-guest system from cyclodextrin as an absolute water-soluble fluorescence sensor for aluminium ions: synthesis, characterization and sensing activity $\uparrow$}

Zengchen Liu, (D) *a Kai Ren, ${ }^{a}$ Yahong Chen, ${ }^{a}$ Yanxia Li, ${ }^{a}$ Jianping Xie, ${ }^{a}$ Yongjie Ding, ${ }^{a}$ Lili Li, ${ }^{a}$ Ke Li, ${ }^{a}$ Wenping Zhu, ${ }^{a}$ Weijie Yang ${ }^{a}$ and Zhihong $\mathrm{Xu}^{\mathrm{b}}$

In the study, an organic molecule derived from paeonol and anthraniloyl hydrazine ( $L$ ) was synthesized via a Schiff-base reaction. Moreover, a host-guest system composed of TEPA- $\beta$-CD and $L$ was self-assembled via supramolecular interactions. The organic molecule and host-guest system were characterized via NMR, HRMS, IR, and SEM. In addition, the internal structure of the system was clearly observed via HRTEM. The host-guest system exhibited absolute water-solubility. Via the fluorescence behavior toward several metal ions in aqueous media without organic solvents $(\mathrm{pH}=7.2)$, the host-guest system showed high selectivity toward $\mathrm{Al}^{3+}$ over other commonly coexistent metal ions. Therefore, this host-guest system can be used as a fluorescence sensor for aluminium ions in aqueous media. Moreover, a large binding constant $\left(5.84 \times 10^{4} \mathrm{M}^{-1}\right)$ between the sensor and $\mathrm{Al}^{3+}$ was calculated via a fluorescent titration experiment. Additionally, the absolute water-solubility activity effectively enhanced the application value of the host-guest system for tracking and detection of $\mathrm{Al}^{3+}$.

\section{Introduction}

As highly selective and sensitive molecules, fluorescence sensors are of great importance and exhibit potential applications for the detection of metal ions in biological systems and the environment. ${ }^{1}$ Among the metal ions, aluminium ions widely exist in the environment, and aluminium is the third most abundant element in the Earth's crust. Aluminium ions affect the activity of gastrointestinal enzymes and excess aluminium ions are toxic to the central nervous system. Moreover, they lead to many diseases, such as Alzheimer's and Parkinson's disease, as well as bone softening and chronic renal failure. ${ }^{2}$ Thus, aluminium ions are attracting increasing attention. To date, numerous fluorescence sensors toward aluminium ions have been synthesized and their fluorescence sensing activities have also been investigated. However, these sensors are mainly derived from organic molecules; thus, they exhibit low water-solubility and potentially high toxicity.

Supramolecular systems from porphyrins, phthalocyanines, and cyclodextrin have been widely studied in the bioimaging, optical, and electronic fields and as biological hybrid

${ }^{a}$ College of Chemistry and Chemical Engineering, The Key Laboratory of Rare Earth Functional Materials and Applications, Zhoukou Normal University, Zhoukou 466001, P. R. China. E-mail: liuzengchen@zknu.cn

${ }^{b}$ Key Laboratory of Chemo/Biosensing and Detection, School of Chemistry and Chemical Engineering, Xuchang University, 461000, P. R. China

$\dagger$ Electronic supplementary information (ESI) available: ${ }^{1} \mathrm{H}$ NMR, ${ }^{13} \mathrm{C}$ NMR and HRMS spectra of L. See DOI: 10.1039/c7ra06915d nanomaterials, biological sensors, and drug delivery systems. ${ }^{3-7}$ Supramolecular systems can assembled to form unique architectures via supramolecular interactions such as hydrogen bonds, van der Waals forces, Coulomb force, and $\pi-\pi$ conjugation, which display particular structures and special performances. ${ }^{\mathbf{8} 9}$ As one of the most important applied forces in supramolecular chemistry, host-guest interactions can realize supramolecular self-assembly and disassembly via diverse stimuli. During the past decade, some host-guest supramolecular self-assembly materials have been synthesized and their structure-function relationships have been well studied. ${ }^{\mathbf{1 0 - 1 2}}$ Cyclodextrin, which is a favorable water-soluble host material, is usually used to construct various supramolecular selfassembly systems with appropriate guest molecules such as azobenzene, vanillin, and adamantine. ${ }^{\mathbf{1 3 , 1 4}}$ Host-guest type superamphiphiles consist of a hydrophilic host and a hydrophobic tail guest. Based on the supramolecular self-assembly, water-solubility can be enhanced and the toxicity of the guest is reduced. At present, great efforts have been devoted towards searching novel guest molecules and construction of supramolecular materials with special functions. To date, most researchers just employ simple alkyl chains as the hydrophobic guests that serve as the hydrophobic portion. ${ }^{15}$ Moreover, supramolecular host-guest systems from cyclodextrin are fabricated with specific architectures and are a focus of pharmaceutical research. However, little attention has been paid to the fluorescence activity of these host-guest systems. ${ }^{\mathbf{1 6}}$ 
Herein, a simple organic molecule derived from paeonol was synthesized, which was assembled with $\beta$-cyclodextrin via supramolecular interactions. Based on the self-assembly, a host-guest system was fabricated and systemically characterized. In addition, we clearly observed the clear internal structure of the host-guest system via HRTEM for the first time. In this system, the water-insoluble organic molecule was designed to directly act as the hydrophobic tail of a superamphiphile, which could further self-assemble into the cavity of $\beta$-cyclodextrin in an aqueous solution. The fluorescence sensing activities of the host-guest system were investigated, and it exhibited specific sensing activities toward aluminium ions in water media.

\section{Results and discussion}

\section{Synthesis of the host-guest system}

The synthetic route for the host-guest system is shown in Scheme 1 and the detailed synthetic process is presented in the Experimental section. Additionally, the host-guest system was characterized via NMR and IR spectroscopy and SEM and HRTEM.

\section{Structural analyses of the host-guest system}

As observed the SEM analysis (Fig. 1), the compound shows a similar surface morphology (multilayered sheet structure) with TEPA- $\beta-C D$, which can assemble into an irregular architecture. The morphology from the SEM image indicates no remarkable change in the surface features of TEPA- $\beta$-CD-L. In addition, to illustrate the successful self-assembly between TEPA- $\beta$-CD and L, HRTEM was utilized to illustrate the clearer structure of the host-guest system (Fig. 2). In the HRTEM image, the obvious difference of alternating dark and bright areas appeared; the interior of the crystal lattice, which is the dark field (more $\mathrm{N}$ element from $\mathrm{L}$ ) representing $\mathrm{L}$, as indicated by the arrow, exhibits a striking contrast with the bright field (TEPA- $\beta-C D)$. Moreover, the diffraction fringe graph $(5 \mathrm{~nm}$ resolution ratio) from TEPA- $\beta$-CD also demonstrates that there are two different substances. Additionally, the peaks of $\mathrm{N}$ and $\mathrm{O}$ from the EDX spectrum overlap (Fig. 2); this indicates that L and

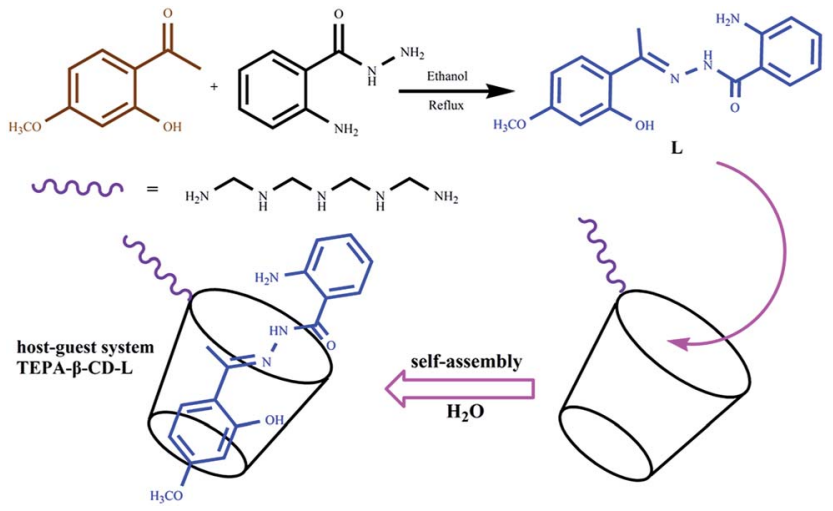

Scheme 1 Synthetic route for the organic molecule $(L)$ and the supramolecular self-assembly host-guest system (TEPA- $\beta$-CD-L).

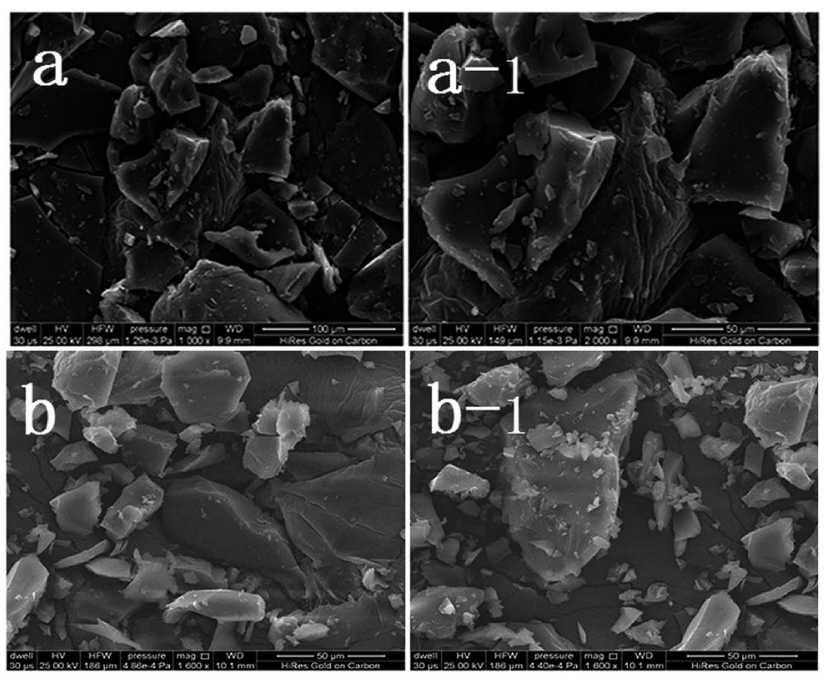

Fig. 1 SEM images of TEPA- $\beta-C D(a$ and $a-1)$ and TEPA- $\beta-C D-L$ (b and $b-1)$.
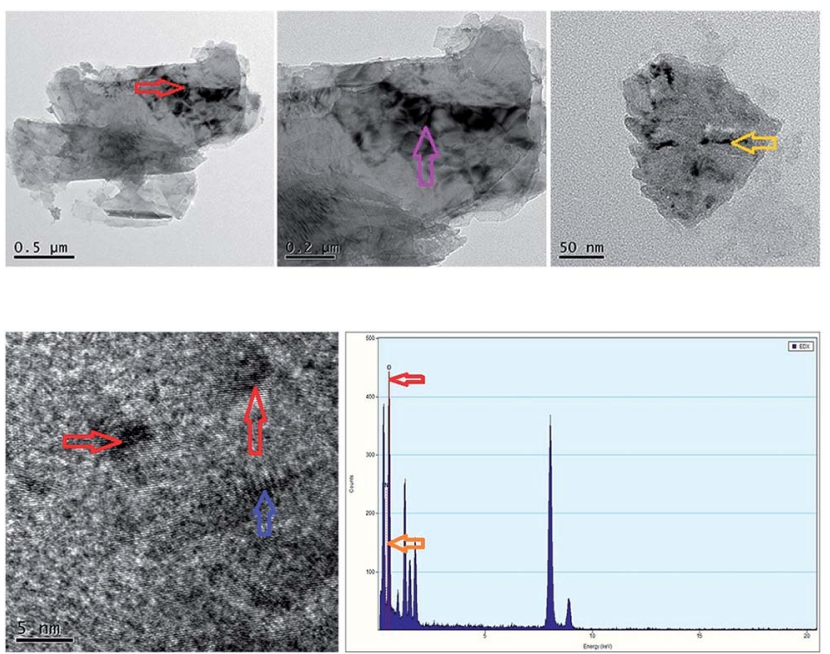

Fig. 2 HRTEM images and EDX spectrum of TEPA- $\beta-C D-L$.

TEPA- $\beta$-CD combine together via host-guest interactions. Thus, it is difficult to distinguish $\mathrm{N}$ and $\mathrm{O}$.

\section{Fluorescence spectral analysis and response mechanism inference}

To confirm the fluorescence selectivity of TEPA- $\beta$-CD-L toward various metal ions $\left(\mathrm{Al}^{3+}, \mathrm{Zn}^{2+}, \mathrm{Cu}^{2+}, \mathrm{Cd}^{2+}, \mathrm{Hg}^{2+}, \mathrm{Mg}^{2+}, \mathrm{K}^{+}, \mathrm{Mn}^{2+}\right.$, and $\mathrm{Cr}^{3+}$ ), its fluorescence behavior (Fig. 3) was investigated upon the addition of metal ions in aqueous media $(\mathrm{pH}=7.2)$. The water-soluble compound TEPA- $\beta$-CD-L exhibited a significant blue fluorescence emission band at $400 \mathrm{~nm}$ in the aqueous media ( $\mathrm{pH}=7.2)$. After the addition of various metal ions, only $\mathrm{Al}^{3+}$ led to an obvious fluorescence emissive wavelength shift from $400 \mathrm{~nm}$ to $420 \mathrm{~nm}$ along with a change in fluorescence from blue to green under UV light in pure aqueous media. Moreover, the fluorescence intensity decreased. Additionally, 


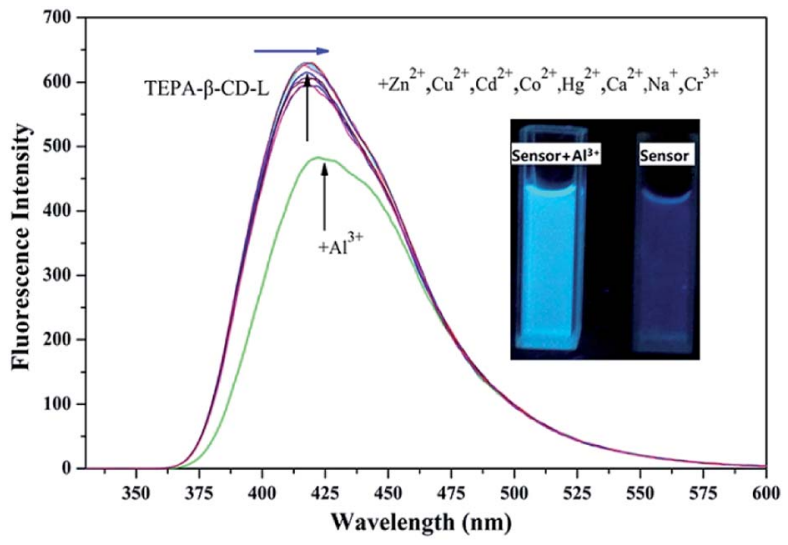

Fig. 3 Fluorescence selectivity spectra of TEPA- $\beta-C D-L$ with various metal ions. Excitation wavelength is $320 \mathrm{~nm}$.

other metal ions did not cause obvious fluorescence emissive changes in TEPA- $\beta$-CD-L. This experiment proved that the coordination between $\mathrm{Al}^{3+}$ and TEPA- $\beta$-CD-L caused the shift in the emissive wavelength of TEPA- $\beta-\mathrm{CD}-\mathrm{L}$ in aqueous media. Thus, the fluorescence behavior of TEPA- $\beta$-CD-L preliminarily indicates that water-soluble TEPA- $\beta$-CD-L could be utilized as a fluorescence probe for $\mathrm{Al}^{3+}$ in aqueous media.

The high selectivity of TEPA- $\beta$-CD-L toward $\mathrm{Al}^{3+}$ was also investigated via fluorescence competitive experiments with other cations (Fig. 4). Herein, 2 equivalents of $\mathrm{Al}^{3+}$ was added to an aqueous solution of TEPA- $\beta$-CD-L $\left(1.0 \times 10^{-6} \mathrm{M}\right)$, and then, an equivalent amount of other metal ions $\left(\mathrm{Zn}^{2+}, \mathrm{Cu}^{2+}, \mathrm{Cd}^{2+}\right.$, $\mathrm{Hg}^{2+}, \mathrm{Mg}^{2+}, \mathrm{K}^{+}, \mathrm{Mn}^{2+}$, and $\mathrm{Cr}^{3+}$ ) was also added to the solution. The change in fluorescence intensity was obtained. As shown in the histogram, only the addition of $\mathrm{Cu}^{2+}$ led to a slight fluorescence intensity decrease, and with addition of other metal ions, no significant variation in the fluorescence emission was observed in the fluorescence property of TEPA- $\beta-\mathrm{CD}-\mathrm{L}-\mathrm{Al}^{3+}$. All the fluorescence spectra demonstrate the high selectivity of TEPA- $\beta$-CD-L toward $\mathrm{Al}^{3+}$ over other co-existent metal ions in aqueous media.

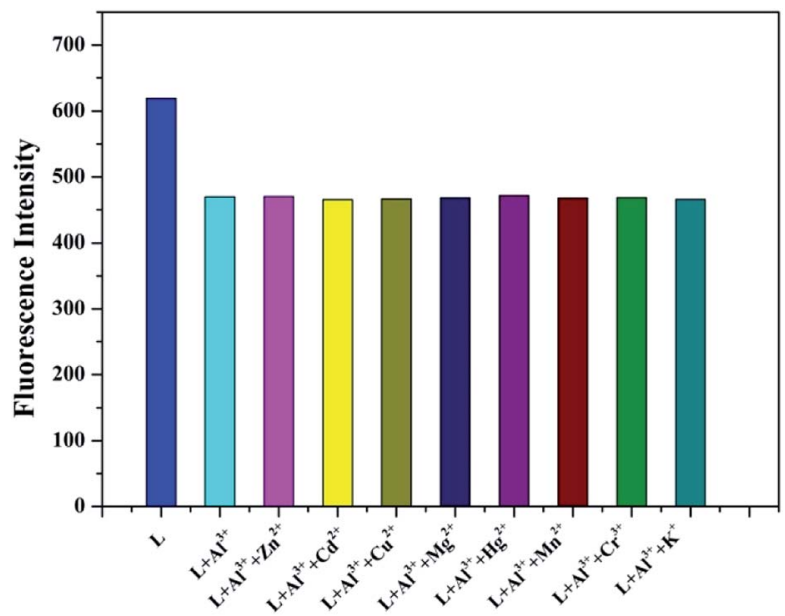

Fig. 4 Fluorescence competition of $\mathrm{Al}^{3+}$ with other metal ions.
The fluorescence titration experiment (Fig. 5a) of TEPA- $\beta$ $\mathrm{CD}-\mathrm{L}$ with $\mathrm{Al}^{3+}$ was performed in aqueous media $(\mathrm{pH}=7.2)$ at room temperature. Upon the addition of $\mathrm{Al}^{3+}$, the fluorescence signal at $405 \mathrm{~nm}$ significantly changed (decreased and red shifted). Thus, it is clear that the binding between TEPA- $\beta$-CD-L and $\mathrm{Al}^{3+}$ induces a fluorescence change in the TEPA- $\beta-\mathrm{CD}-\mathrm{L}$ sensor. It is also obvious that the fluorescence change is accompanied by a fluorescence emission wavelength shift from $405 \mathrm{~nm}$ to $425 \mathrm{~nm}$. As shown in Fig. 5b, the association constant between TEPA- $\beta$-CD-L and $\mathrm{Al}^{3+}$ was estimated to be $5.84 \times 10^{4}$ $\mathrm{M}^{-1}$ in aqueous media $(\mathrm{pH}=7.2)$ by fitting the data to the Benesi-Hildebrand expression with a good linear relationship. In addition, the detection limit of the sensor toward $\mathrm{Al}^{3+}$ was also tested via fluorescence spectroscopy, and the detection limit was as low as 0.1 micromolar in aqueous media.

As an important recognition unit, Schiff-base molecules have been widely used for the development of fluorescent sensors based on various sensing mechanisms. From the fluorescence behaviour of the sensor toward $\mathrm{Al}^{3+}$, its sensing mechanism was preliminarily concluded. TEPA- $\beta$-CD-L exhibits blue fluorescence, and after the addition of $\mathrm{Al}^{3+}$, green fluorescence appears, accompanied by a red shift of its emissive wavelength. Based on this fluorescence activity, the fluorescence resonance energy transfer mechanism is applicable to the sensing process of the sensor binding to $\mathrm{Al}^{3+}$.

\section{UV-vis spectrum investigation}

The UV-vis absorption titration spectrum in aqueous media $(\mathrm{pH}$ $=7.2$ ) was examined to evidence the interactions between TEPA$\beta$-CD-L and $\mathrm{Al}^{3+}$ (Fig. 6). In the absorption spectrum in the presence of $\mathrm{Al}^{3+}$, the absorption peaks show a significant blue shift at $395 \mathrm{~nm}$ and $325 \mathrm{~nm}\left(\mathrm{n}-\pi^{*}\right)$ with an evident increase in the absorption intensity. This can be attributed to the formation of a stable complex of $\mathrm{Al}^{3+}$ with TEPA- $\beta$-CD-L. In addition, the absorption peak $\left(\pi-\pi^{*}\right)$ intensity at $205 \mathrm{~nm}$ decreased gradually with the addition of $\mathrm{Al}^{3+}$ accompanied by a red shift in the peak position; this clearly indicated the coordination of $\mathrm{Al}^{3+}$ with the hydroxyl group (auxochrome) from L.

\section{Application of the sensor in the environment and filter paper experiment}

Cyclodextrin cannot enter cells; thus, to explore the efficacy of this probe (TEPA- $\beta$-CD-L) for the detection of $\mathrm{Al}^{3+}$ ions in real samples, the sensing effect of the absolute water-soluble TEPA-

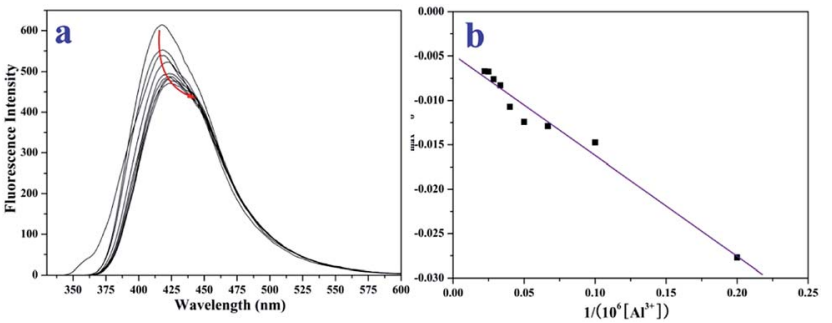

Fig. 5 Fluorescence titration experiment (a) and binding constant from the linear Benesi-Hildebrand expression (b). 


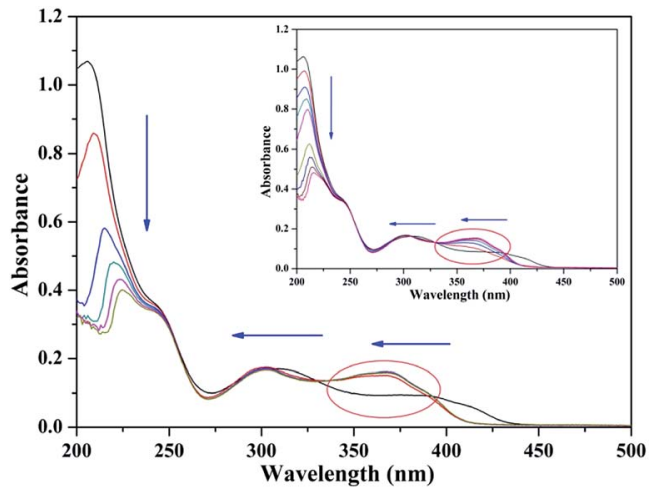

Fig. 6 UV-vis addition spectra of TEPA- $\beta-C D-L$ with $\mathrm{Al}^{3+}$ in aqueous media.

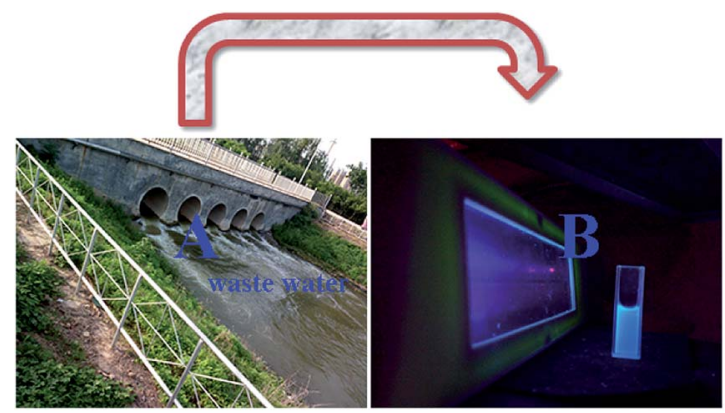

Fig. 7 (A) Real waste water in the environment and (B) image of the fluorescence of waste water containing various metal ions under UV light.

$\beta$-CD-L toward $\mathrm{Al}^{3+}$ in the environment was determined. As shown in Fig. 7, various metal ions containing $\mathrm{Al}^{3+}$ were added to the waste water in real environment (A), and then, sensor was added to the solution and intense fluorescence under UV light was observed (B).

Additionally, filter paper was soaked in an aqueous solution of TEPA- $\beta$-CD-L, and blue fluorescence was observed. Then, several drops of an $\mathrm{Al}^{3+}$ aqueous solution were dropped onto the filter paper and blue green fluorescence was observed. This experimental result (Fig. 8) is in accordance with the fluorescence spectra. Thus, this absolute water-soluble host-guest system could be applied in the environment for the analysis of $\mathrm{Al}^{3+}$.

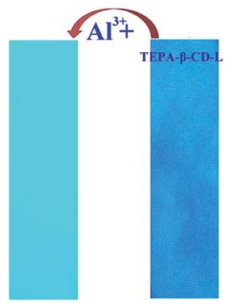

Fig. 8 Fluorescence of filter paper in a solution of $\mathrm{L}$ and $\mathrm{L}+\mathrm{Al}^{3+}$ under UV light.

\section{Experimental}

\section{Materials and physical measurements}

$\beta$-Cyclodextrin was purchased from Shandong Binzhou Zhiyuan Biotechnology Co., Ltd. Paeonol and anthraniloyl hydrazine were purchased from Aladdin Co., Ltd, Shanghai. All chemicals containing solvents were of reagent grade and used without further purification.

${ }^{1} \mathrm{H}$ NMR and ${ }^{13} \mathrm{C}$ NMR spectra were obtained using a Varian VR400-MHz spectrometer with TMS as an internal standard. The melting point of the compound was determined using a Beijing XT4-100X microscopic melting point apparatus. UV-vis spectra were obtained using a Perkin-Elmer Lambda-35 UV-vis spectrophotometer. Fluorescence spectra were obtained via a Cary Eclipse spectrophotometer at room temperature. Scanning electron microscopy was conducted using an FEI Quanta 200. HRTEM was performed using a Tecnai G2 F20 field emission gun transmission electron microscope.

All spectroscopic measurements were performed in aqueous solution $(\mathrm{pH}=7.2)$ and $\mathrm{pH}$ was controlled using HEPES buffer solution.

Stock solutions $\left(1.0 \times 10^{-3} \mathrm{M}\right)$ of the metal ions (metal nitrate) were prepared in double-distilled water. The stock solution of $0.3 \times 10^{-3} \mathrm{M}$ TEPA- $\beta$-CD-L was prepared in pure distilled-water, and $\mathrm{pH}$ was controlled using HEPES buffer solution $(\mathrm{pH}=7.2)$. In the titration experiments, $2 \mathrm{~mL}$ water solution containing $20 \mu \mathrm{L}$ solution of TEPA- $\beta$-CD-L $\left(1.0 \times 10^{-3}\right.$ M) was filled in a quartz optical cell with a $1 \mathrm{~cm}$ optical path length. Then, $20 \mu \mathrm{L}$ of $\mathrm{Al}^{3+}$ stock solution was added to the compound solution with a micro-pipette. Spectral data was obtained at 1 min after the addition. In the selectivity experiment, the test samples were prepared by placing appropriate amounts of metal ion stock solution into $2 \mathrm{~mL}$ aqueous solution of TEPA- $\beta$-CD-L $(20 \mu \mathrm{L})$. For fluorescence measurements, the excitation wavelength was $320 \mathrm{~nm}$.

The binding constant between TEPA- $\beta-\mathrm{CD}-\mathrm{L}$ and $\mathrm{Al}^{3+}$ was calculated using the linear Benesi-Hildebrand expression. ${ }^{18}$

$$
\frac{1}{F-F_{0}}=\frac{1}{K_{\mathrm{S}}} \frac{1}{\left[F_{\max }-F_{0}\right]\left[\mathrm{Al}^{3+}\right]}+\frac{1}{F_{\max }-F_{0}}
$$

where $F$ is the change in fluorescence intensity in the presence of $\mathrm{Al}^{3+}$ at $410 \mathrm{~nm}, K_{\mathrm{s}}$ is the stability constant, and $F_{0}$ is the fluorescence intensity of $\mathrm{L}$ in the absence of $\mathrm{Al}^{3+}$. On the basis of the plot of $1 /\left(F-F_{0}\right)$ versus $1 /\left[\mathrm{Al}^{3+}\right]$, the stability constant was obtained.

\section{Synthesis of tetraethylenepentamine $\beta$-cyclodextrin derivate} (TEPA- $\beta$-CD)

The tetraethylenepentamine $\beta$-cyclodextrin derivate (TEPA- $\beta$ CD) was synthesized according to a reported method, ${ }^{17}$ and it was directly used without further characterization.

\section{Synthesis of guest molecule derived from paeonol and anthraniloyl hydrazine (L)}

The synthetic route for the paeonol-anthraniloyl hydrazine Schiff-base molecule is shown in Scheme 1. An ethanol ethanol/ 
$\mathrm{H}_{2} \mathrm{O}$ solution $(1: 1,12 \mathrm{~mL})$ of anthraniloyl hydrazine $(1 \mathrm{mmol}$, $0.1510 \mathrm{~g})$ was added to a $(8 \mathrm{~mL})$ solution containing paeonol ( $1 \mathrm{mmol}, 0.166 \mathrm{~g})$. Then, the solution was refluxed for $9 \mathrm{~h}$ and cooled to room temperature. The mixture was filtered and dried under vacuum. Recrystallization from $\mathrm{C}_{2} \mathrm{H}_{5} \mathrm{OH} / \mathrm{H}_{2} \mathrm{O}(\mathrm{V}: \mathrm{V}=$ $1: 2$ ) gave the target product, the paeonol-anthraniloyl hydrazine Schiff-base (L), which was dried under vacuum. Yield, 36.9\%. mp: 200.4-203.5 ${ }^{\circ}$ C. ${ }^{1} \mathrm{H}$ NMR (Fig. S1, $\dagger$ DMSO- $\mathrm{d}_{6} 400$ $\mathrm{MHz}): \delta 13.80\left(1 \mathrm{H}, \mathrm{s},-\mathrm{N}^{10}-\mathrm{H}\right), \delta 11.00\left(1 \mathrm{H}, \mathrm{s},-\mathrm{O}^{11}-\mathrm{H}\right), \delta 7.58-$ $7.64\left(1 \mathrm{H}, \mathrm{d},-\mathrm{C}^{5}-\mathrm{H}\right), \delta 7.51-7.57\left(1 \mathrm{H}, \mathrm{d},-\mathrm{C}^{4}-\mathrm{H}\right), \delta 7.20-7.25(1 \mathrm{H}$, $\left.\mathrm{m},-\mathrm{C}^{16}-\mathrm{H}\right), \delta 6.75-6.80\left(1 \mathrm{H}, \mathrm{d},-\mathrm{C}^{14}-\mathrm{H}\right), \delta 6.58-6.61(1 \mathrm{H}, \mathrm{m}$, $\left.-\mathrm{C}^{15}-\mathrm{H}\right), \delta$ 6.45-6.50 (1H, d, $\left.-\mathrm{C}^{17}-\mathrm{H}\right), \delta 6.43\left(1 \mathrm{H}, \mathrm{s},-\mathrm{C}^{7}-\mathrm{H}\right)$, $\delta 3.73\left(3 \mathrm{H}, \mathrm{s},-\mathrm{C}^{19}-\mathrm{H}\right), \delta 3.33\left(3 \mathrm{H}, \mathrm{s},-\mathrm{C}^{2}-\mathrm{H}\right), \delta 2.40\left(2 \mathrm{H}, \mathrm{s},-\mathrm{N}^{21}\right.$ H). ${ }^{13} \mathrm{C}$ NMR (Fig. S2, $\dagger$ DMSO-d $6400 \mathrm{MHz}$ ): 167, 162, 160, 158, $151,133,131,130,117,115,114,113,107,102,58,15$. HRMS (Fig. S3†): $m / z=300.13,[\mathrm{~L}+\mathrm{H}]^{+}, m / z=322.1158,[\mathrm{~L}+\mathrm{Na}+\mathrm{H}]^{+}$.

\section{Synthesis of the host-guest system derived from} tetraethylenepentamine and L (TEPA- $\beta-C D-L)$

$1.20 \mathrm{mmol}$ paeonol-anthraniloyl hydrazine Schiff-base (L) was directly added to an $\mathrm{H}_{2} \mathrm{O}$ solution $(25 \mathrm{~mL})$ containing TEPA- $\beta$ $\mathrm{CD}(1 \mathrm{mmol})$, and then the solution was stirred for $12 \mathrm{~h}$ at $75^{\circ} \mathrm{C}$. The mixture was filtered and concentrated under vacuum. Then $20 \mathrm{~mL}$ ethanol was added to the solution and the solid separated. The precipitate was filtered and recrystallized from $\mathrm{H}_{2} \mathrm{O}$ / ethanol $(\mathrm{v} / \mathrm{v}=1: 5)$ to give tetraethylenepentamine- $\beta$ cyclodextrin-4-diethylamine salicylaldehyde (TEPA- $\beta-\mathrm{CD}-\mathrm{L}$ ). TEPA- $\beta-C D-L$ yield, $35 \%$. To confirm the fabrication of the host-guest system, the ${ }^{1} \mathrm{H}$ NMR spectrum of the target molecule was measured. As shown in Fig. 9, after purification the target molecule can very well be dissolved in $\mathrm{H}_{2} \mathrm{O}$. The ${ }^{1} \mathrm{H}$ NMR spectrum of the target molecule contains characteristics of both TEPA- $\beta$-CD and L, which demonstrates the successful establishment of the host-guest system. From the FT-IR analysis (Fig. 10), TEPA- $\beta$-CD-L exhibits similar peaks with TEPA- $\beta$-CD; meanwhile, several characteristic peaks from $\mathrm{L}$ are included in

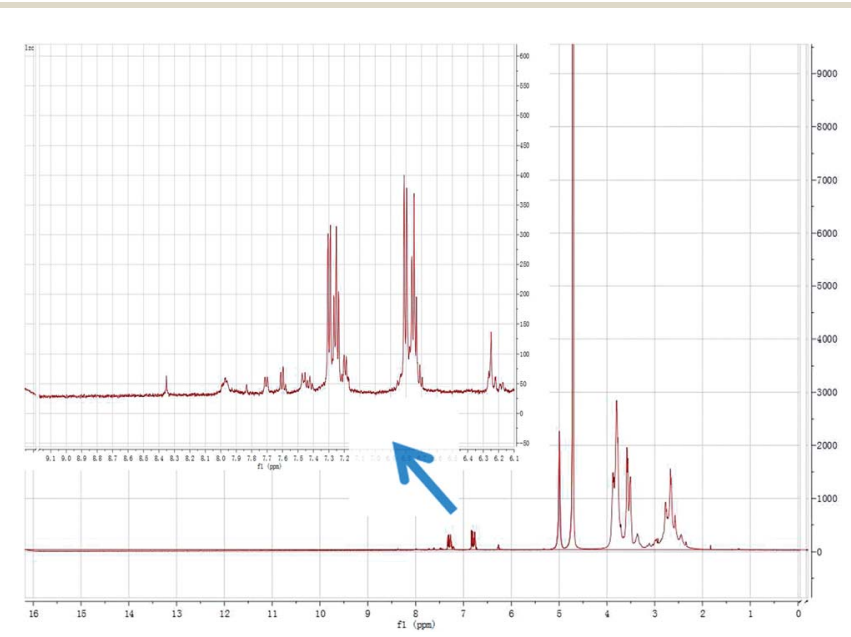

Fig. 9 The ${ }^{1} \mathrm{H}$ NMR spectrum of the host-guest system tetraethylenepentamine- $\beta$-cyclodextrin-4-diethylamine salicylaldehyde sensor (TEPA- $\beta-C D-L$ ) in $\mathrm{H}_{2} \mathrm{O}-\mathrm{d}_{2}$ media.

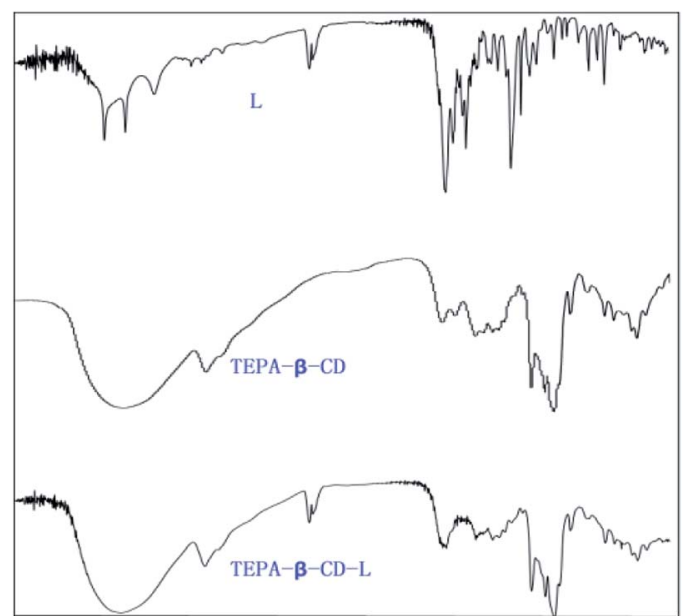

Fig. 10 The IR spectra of $L, T E P A-\beta-C D$, and TEPA- $\beta-C D-L$.

the spectrum of TEPA- $\beta$-CD-L, which illustrates that $\mathrm{L}$ entered into the cavity of TEPA- $\beta-\mathrm{CD}$ and the host-guest system was successfully formed.

\section{Conclusions}

In summary, an absolutely water-soluble host-guest system derived from $\beta$-cyclodextrin and an organic molecule was fabricated, and it exhibited high fluorescence selectivity toward $\mathrm{Al}^{3+}$ in aqueous media. The host-guest system was characterized via SEM, HRTEM, and NMR. Moreover, the sensor exhibits high selectivity and good sensitivity. Furthermore, owing to its absolute water-solubility, it can be used to discover and detect $\mathrm{Al}^{3+}$ in natural environments such as waste water and biology systems. Thus, this investigation demonstrates the potential application of the TEPA- $\beta$-CD-L host-guest system in biological and environment fields for the tracking and detection of $\mathrm{Al}^{3+}$.

\section{Acknowledgements}

This work was supported by the Natural Science Foundation of China (21477167), Young and middle-aged backbone teachers plan of Zhoukou Normal University, the Natural Science Foundation of Education Department of Henan Province of China (No. 16B416001), We acknowledge the Joint Program for the Fostering Talents of National Natural Science Foundation of China and Henan Province (U1304202), the Program for Science and Technology Innovation Talents in Universities of Henan Province (15HASTIT002), the Henan Province Science and Technology Project (152102210343), the Key Program in Universities of Henan Province (15B150016), and the Foundation for Excellent Youths of Xuchang University for financial support.

\section{Notes and references}

1 (a) J. F. Li, Y. Z. Wu, F. Y. song, G. Wei, Y. X. Cheng and C. J. Zhu, J. Mater. Chem., 2012, 22, 478; (b) H. Zhu, 
J. L. Fan, B. H. Wang and X. J. Peng, Chem. Soc. Rev., 2015, 44, 4337; (c) J. Li, D. J. Yim, W. D. Jang and J. Y. Yoon, Chem. Soc. Rev., 2017, 46, 2437; (d) S. K. Sahoo, D. Sharma, R. K. Bera, G. Crisponi and J. F. Callan, Chem. Soc. Rev., 2012, 41, 7195; (e) Y. Zhou, J. F. Zhang and J. Y. Yoon, Chem. Rev., 2014, 114, 5511.

2 (a) O. Tavakoli and H. Yoshida, Environ. Sci. Technol., 2005, 39, 2357; (b) D. P. Perl and A. R. Brody, Science, 1980, 208, 297; (c) G. D. Fasman, Coord. Chem. Rev., 1996, 149, 125; (d) Y. Liu, P. Liang and L. Guo, Talanta, 2005, 68, 25.

3 (a) T. Sun, Q. B. Wang, Y. K. Bi, X. L. Chen, L. S. Liu, C. H. Ruan, Z. F. Zhao and C. Jiang, J. Mater. Chem. B, 2017, 5, 2644; (b) Y. Liu, C. Y. Yu, H. B. Jin, B. B. Jiang, X. Y. Zhu, Y. F. Zhou, Z. Y. Lu and D. Y. Yan, J. Am. Chem. Soc., 2013, 135, 4765.

4 (a) S. Ishihara, J. Labuta, W. V. Rossom, D. Ishikawa, K. Minami, J. P. Hill and K. Ariga, Phys. Chem. Chem. Phys., 2014, 16, 9713; (b) T. Tanaka and A. Osuka, Chem. Soc. Rev., 2015, 44, 943; (c) M. Titi, B. K. Tripuramallu and I. Goldberg, CrystEngComm, 2016, 18, 3318.

5 (a) J. Liang, X. Dong, C. Wei, D. L. Kong, T. J. Liu and F. Lv, $R S C A d v .$, 2017, 7, 6501; (b) J. L. Kan, Y. L. Chen, J. Gao, L. Wan, T. J. Lei, P. Ma, J. Z. Jiang and J. Mater, Chem, 2012, 22, 15695; (c) D. Topkaya, F. Dumoulin, V. Ahsen and U. Isci, Dalton Trans., 2014, 43, 2032.

6 R. R. Sun, L. Wang, J. Tian, X. M. Zhang and J. Z. Jiang, Nanoscale, 2012, 4, 6990.

7 (a) R. I. Khan and K. Pitchumani, Green Chem., 2016, 18, 5518; (b) L. M. Cao, X. J. Shi, Y. C. Cui, W. K. Yang, G. J. Chen, L. Yuan and H. Chen, Polym. Chem., 2016, 7, 5139; (c) C. B. Rodell, C. B. Highley, M. H. Chen, N. N. dusaj, C. Wang, L. Han and J. A. Burdick, Soft Matter, 2016, 12, 7839.

8 (a) F. C. Leung, S. Y. Leung, C. Y. Chung and V. W. Yam, J. Am. Chem. Soc., 2016, 138, 2989; (b) A. F. Stewart, B. P. Gagnon and G. C. Walker, Langmuir, 2015, 31, 6902; (c) A. Lukach, K. Liu, H. Therien-Aubin and E. Kumacheva, J. Am. Chem. Soc., 2012, 134, 18853; (d) J. Wu, Y. Xu, D. F. Li, X. Ma and H. Tian, Chem. Commun., 2017, 53, 4577. 9 (a) C. X. Xu, L. Yuan, G. Z. Liang and A. J. Gu, J. Mater. Chem. C, 2016, 4, 3175; (b) H. Yao and C. Fukui, J. Mater. Chem. C, 2016, 4, 2945; (c) B. D. Wagner, Phys. Chem. Chem. Phys., 2012, 14, 8825 .
10 (a) J. Teyssandier, S. D. Feyter and K. S. Mali, Chem. Commun., 2016, 52, 11465; (b) P. F. Wei, X. Z. Yan and F. H. Huang, Chem. Soc. Rev., 2015, 44, 815; (c) T. Ogoshi and T. Yamagishi, Chem. Commun., 2014, 50, 4776.

11 (a) D. A. Fowler, C. R. Pfeiffer, S. J. Teat, C. M. Beavers, G. A. Baker and J. L. Atwood, CrystEngComm, 2014, 16, 6010; (b) R. M. Ariza, L. G. Suarez, W. Verboom and J. Huskens, J. Mater. Chem. B, 2017, 5, 36.

12 (a) Y. K. Kim, Y. H. Ko, M. Jung, N. Selvapalam and K. Kim, Photochem. Photobiol. Sci., 2011, 10, 1415; (b) K. Yang, Y. X. Pei, J. Wen and Z. C. Pei, Chem. Commun., 2016, 52, 9316; (c) S. A. Ikbal, S. Brahma and S. P. Rath, Chem. Commun., 2014, 50, 14037.

13 (a) L. P. Long, J. Y. Jin, Y. Zhang, R. H. Yang and K. M. Wang, Analyst, 2008, 133, 1201; (b) N. Smiljanic, D. Yockot, V. Cendret, M. F. Heude, V. Moreau and F. D. Pilard, Carbohydr. Chem., 2012, 37, 37; (c) P. Neirynck, S. P. Jonkheijm, L. G. Milroy, P. Cigler and L. Brunsveld, J. Mater. Chem. B, 2015, 3, 539.

14 (a) G. Yang, Z. Yang, C. G. Mu, X. D. Fan, W. Tian and Q. Wang, Polym. Chem., 2015, 6, 3382; (b) M. M. Zhang, W. Shen, Q. Q. Xiong, H. W. Wang, Z. M. Zhou, W. J. Chen and Q. Q. Zhang, RSC Adv., 2015, 5, 28133; (c) L. X. Zhang, H. Zhang, F. Gao, H. Y. Peng, Y. H. Ruan, Y. Z. Xu and W. G. Weng, RSC Adv., 2015, 5, 12007.

15 (a) X. E. Ma, N. Z. Zhou, T. Z. Zhang, Z. C. Guo, W. J. Hu, C. H. Zhu, D. D. Ma and N. Gu, RSC Adv., 2016, 6, 13129; (b) E. M. Nehls, A. M. Rosales and K. S. Anseth, J. Mater. Chem. B, 2016, 4, 1035; (c) C. C. Zhou, J. B. Huang and Y. Yan, Soft Matter, 2016, 12, 1579; (d) T. Ogoshi, M. Hashizume, T. A. Yamagishi and Y. Nakamoto, Langmuir, 2010, 26, 3169.

16 (a) F. Schibilla, L. Stegemann, C. A. Strassert, F. Rizzo and B. J. Ravoo, Photochem. Photobiol. Sci., 2016, 15, 235; (b) Z. C. Liu, W. J. Yang, Y. X. Li, F. S. Tian and W. P. Zhu, RSC Adv., 2015, 5, 100482.

17 Z. C. Liu, W. P. Zhu, Y. H. Chen, Y. X. Li, Y. J. Ding, W. J. Yang and K. Li, Dalton Trans., 2015, 44, 16528.

18 (a) H. A. Benesi and J. H. Hildebrand, J. Am. Chem. Soc., 1949, 71, 2703; (b) S. Pal, M. Mukherjee, B. Sen, S. K. Mandal, S. Lohar, P. Chattopadhyay and K. Dhara., Chem. Commun., 2015, 51, 4410; (c) M. Mukherjee, B. Sen, S. Pal, M. S. Hundal, S. K. Mandal, A. R. Khuda-Bukhsh and P. Chattopadhyay, RSC Adv., 2013, 3, 19978. 